\title{
A Matched-Pair Longitudinal Study on the Relationship between Maternal Smoking and Head Circumference of Newborns
}

\author{
Masaru Miyao, Masashi Furuta, Yoshie Matsushita, \\ Miyoko Ogiso, Shin'ya Ishihara and Pern Chian Teo \\ Department of Public Health, Nagoya University School of \\ Medicine, Nagoya 466
}

Miyao, M., Furuta, M., Matsushita, Y., Ogiso, M., Ishinara, S. and Teo, P. C. A Matched-Pair Longitudinal Study on the Relationship between Maternal Smoking and Head Circumference of Newborns. Tohoku J. Exp. Med., 1995, 175 (2), 135-137 — The relationship between maternal smoking and the head circumference of newborns were analyzed using a matched-pair longitudinal method. For the study, data was collected from Japanese primiparas in Aichi, Japan. Forty-seven smoking and nonsmoking mothers were matched using multivariate caliper matching for birth weight and gender for their newborns, and gestational period and age for the gravidas. Significantly smaller head circumferences of the newborns from the smoking mothers were observed.__ smoking; newborn head circumference; maternal health; matched-pair longitudinal study

It is well documented that smoking in gravidas has detrimental effects on their newborns causing decreased birth weights, head and chest circumferences, amongst others (US DHHS 1980; Haste et al. 1991; Day et al. 1992; Lam et al. 1992; Goldenberg et al. 1993). Obviously, the head circumference of newborns is important. However, to date there has been no research revealing whether in addition to a proportional decrease of the whole body, a specific decrease in head circumference occurs. Also in those reports, confounding factors like birth weight, gestation period and the gravidas' age have not been taken into account. To clarify these issues, we studied the relationship between smoking in gravidas and head circumferences of their newborns using a matched-pair longitudinal method.

We surveyed 508 Japanese primiparas in 11 hospitals in Aichi, Japan who gave birth in the two years from April 1990 to March 1992. We selected smoking primiparas who did not have multiple births, caesarean sections, vacuum extraction, breech presentation, nor those who had complications, nor experienced fetal or neonatal deaths. Only those who gave birth by spontaneous delivery were chosen. As shown in Table 1 , there were 47 women who smoked during gestation, and they smoked 5 to 40 cigarettes per day, with a mean of 8.7 (S.D.: \pm 6.6 ). The small number of cases meant that further classification for number of cigarettes smoked was not possible. For the nonsmoking group, we excluded women whose husbands smoked in their proximity even after their partner recognized the pregnancy. All pregnancies were observed from the first visit to the obstetricians, to

Received April 8, 1994; revision accepted for publication October 25, 1994.

Address for reprints: Masaru Miyao, M.D., Department of Public Health, Nagoya University School of Medicine, 65 Tsurumai-cho, Showa-ku, Nagoya 466, Japan. 
TABLE 1. Comparison of smoking and nonsmoking gravidas, and their newborns

\begin{tabular}{lccc}
\hline \multicolumn{1}{c}{ Gravidas } & $\begin{array}{c}\text { Smoking } \\
(n=47)\end{array}$ & $\begin{array}{c}\text { Nonsmoking } \\
(n=47)\end{array}$ & $p^{\mathrm{a}}$ \\
\hline Gestation period (weeks) & $39.2 \pm 1.3^{\mathrm{b}}$ & $39.3 \pm 1.3$ & n.s. \\
Age (years) & $27.2 \pm 4.7$ & $27.1 \pm 3.4$ & n.s. \\
No. of cigarettes/day & $8.7 \pm 6.6$ & - & - \\
\hline \multicolumn{1}{c}{ Newborns } & Smoking & Nonsmoking & $p$ \\
\hline Birthweight (g) & $2,959 \pm 289$ & $2,965 \pm 289$ & n.s. \\
Head circumference (cm) & $32.58 \pm 1.05$ & $33.36 \pm 1.01$ & 0.001 \\
Gender male & 23 & 23 & - \\
\multicolumn{1}{c}{ female } & 24 & 24 & - \\
\hline
\end{tabular}

${ }^{\mathrm{a}} p$ values were analyzed by paired $t$-test; n.s., not significant.

${ }^{\mathrm{b}}$ mean \pm S.D.

delivery, and the smoking habits of the women and their partners were verified at their monthly checks. We measured the newborns' birth weights and head circumferences (frontooccipitalis only) immediately after delivery. Using multivariate caliper matching (Althauser and Rubin 1970), 47 control pairs were matched for gender and birth weight $( \pm 100 \mathrm{~g})$ for the newborns, and gestational period ( \pm 1 week) and age $( \pm 5$ years $)$ for the gravidas. The controls were listed in a random order in a computer database, and the first matching nonsmoking primipara and child falling between the upper and lower limits were chosen as the smoking primiparas' control. These controls were taken from 419 confirmed nonsmoking primiparas who gave birth in the same period. The anthropometric measurement and gestation period of their newborns were then compared to those of the smokers.

In both groups of newborns, there were 23 males and 24 females each. The mean birth weight of babies born to smoking mothers was 2,959 (s.D.: \pm 289 ) g, compared to 2,965 (s.D.: \pm 289$) \mathrm{g}$ for the control newborns. The gestation periods were 39.2 (s.D.: \pm 1.3 ) weeks and 39.3 (S.D.: \pm 1.3 ) weeks, and the ages of the mothers were 27.2 (S.D.: \pm 4.7 ) years and 27.1 (s.D.: \pm 3.4 ) years for the smoking and nonsmoking mothers, respectively. There were no statistically significant differences for all of the above variables (paired $t$-test). However, when we controlled the above mentioned factors by matching, there were significant differences $(0.77 \mathrm{~cm}, p<0.001$, paired $t$-test) in the head circumferences between the newborns of the smokers and those of the nonsmokers. For the smokers' babies, the mean head circumference was 32.58 (s.D.: \pm 1.05 ) $\mathrm{cm}$, and for the nonsmokers' newborns, it was 33.36 (s.D.: \pm 1.01 ) $\mathrm{cm}$. These head circumferences were different, although they had the same birth weight and same gestation period.

In animal experiments (Card and Mitchell 1979; Hammer and Mitchell 1979), it has been shown that nicotine influences implantation and embryo development in some laboratory animal studies. In rabbits, high concentrations of nicotine markedly decrease the in vitro development of preimplantation embryos and inhibits DNA synthesis (Balling and Beier 1985). In humans, it is thought that maternal tobacco smoking causes placental insufficiencies for amino-acid transport, which may explain fetal intrauterine growth retardation (Sastry 1991). Our result of different head circumferences but the same birth weight and same gestation period differs from a previous report which stated that infants displayed symmetrical fetal growth retardation with regard to anthropometric measurements (US DHHS 1980). 
Dolk (1991) found a predictor of microcephaly during the first year of mental retardation based on head circumference measurements. In that study, newborns with head circumferences less than three standard deviations of the norm were found to be mentally retarded at age seven. We should note that small decreases in head circumference among newborns may not be serious with regard to their mental development. However, taking into account the increasing rate of smoking among young Japanese females, this finding has large social ramifications.

\section{References}

1) Althauser, R.P. \& Rubin, D.B. (1970) The computerized construction of a matched sample. Am. J. Sociol., 76, 325-346.

2) Balling, R. \& Beier, H.M. (1985) Direct effects of nicotine on rabbit preimplantation embryos. Toxicology, 34, 309-313.

3) Card, J.P. \& Mitchell, J.A. (1979) The effects of nicotine on implantation in the rat. Biol. Reprod., 20, 532-539.

4) Day, N., Cornelius, M., Goldschmidt, L., Richardson, G., Robles, N. \& Taylor, P. (1992) The effects of prenatal tobacco and marijuana use on offspring growth from birth through 3 years of age. Neurotoxicol. Teratol., 14, 407-414.

5) Dolk, H. (1991) The predictive value of microcephaly during the first year of life for mental retardation at seven years. Dev. Med. Child. Neurol., 33, 974-983.

6) Goldenberg, R.L., Davis, R.O., Cliver, S.P., Cutter, G.R., Hoffman, H.J., Dubard, M.B. \& Cooper, R.L. (1993) Maternal risk factors and their influence on fetal anthropometric measurements. Am. J. Obstet. Gynecol., 168, 1197-1203.

7) Hammer, R.E. \& Mitchell, J.A. (1979) Nicotine reduces embryo growth, delays implantation, and retards parturition in rats. Biol. Neonate, 35, 290-297.

8) Haste, F.M., Anderson, H.R., Brooke, O.G., Bland, J.M. \& Peacock, J.L. (1991) The effects of smoking and drinking on the anthropometric measurements of neonates. Paediatr. Perinat. Epidemiol., 5, 83-92.

9) Lam, S.K., To, W.K., Duthie, S.J. \& Ma, H.K. (1992) The effect of smoking during pregnancy on the incidence of low birth weight among Chinese parturients. Aust. N.Z. J. Obstet. Gynaecol., 32, 125-128.

10) Sastry, B.V. (1991) Placental toxicology: Tobacco smoke, abused drugs, multiple chemical interactions, and placental function. Reprod. Fertil. Dev., 3, 355-372.

11) US Department of Health and Human Services (1980) The Health Consequences of Smoking for Women: A Report of the Surgeon General. US Department of Health and Human Services, Rockville, Maryland. 